05

\title{
Оптическое усиление в лазерных гетероструктурах с активной областью на основе короткопериодной сверхрешетки InGaAs/InGaAIAs
}

\author{
(С) Л.Я. Карачинский ${ }^{1}$, И.И. Новиков ${ }^{2}$, А.В. Бабичев ${ }^{2}$, А.Г. Гладышев ${ }^{2}$, Е.С. Колодезный ${ }^{2}$ Ф , С.С. Рочас ${ }^{2}$, \\ А.С. Курочкин ${ }^{2}$, Ю.К. Бобрецова ${ }^{3}$, А.А. Климов ${ }^{3}$, Д.В. Денисов ${ }^{4}$, К.О. Воропаев ${ }^{5,6}$, А.С. Ионов ${ }^{6}$, \\ B.Е. Бугров ${ }^{2}$, А.Ю. Егоров ${ }^{2}$ \\ ${ }^{1} \mathrm{OOO} \mathrm{„Коннектор} \mathrm{Оптикс“,}$ \\ 194292 Санкт-Петербург, Россия \\ ${ }^{2}$ Университет ИТМО, \\ 197101 Санкт-Петербург, Россия \\ ${ }^{3}$ Физико-технический институт им. А.Ф. Иофффе РАН, \\ 194021 Санкт-Петербург, Россия \\ ${ }^{4}$ Санкт-Петербургский государственный электротехнический университет „ЛЭТИ“ им. В.И. Ульянова (Ленина), \\ 197022 Санкт-Петербург, Россия \\ ${ }^{5}$ Новгородский государственный университет имени Ярослава Мудрого, \\ 173003 Великий Новгород, Россия \\ ${ }^{6}$ АО „ОКБ-Планета“, \\ 173000 Великий Новгород, Россия \\ ฯ e-mail: evgenii_kolodeznyi@corp.ifmo.ru
}

Поступила в редакцию 21.03.2019 г.

В окончательной редакции 19.08.2019 г.

Принята к публикации 20.08.2019 г.

\begin{abstract}
Предложена и реализована конструкция активной области на основе сверхрешетки InGaAs/InGaAlAs для лазерных диодов спектрального диапазона $1535-1565 \mathrm{~nm}$. Показано, что использование сверхрешетки позволяет увеличить модальное усиление при равных значениях плотности тока накачки в сравнении с типичной конструкцией активной области на основе набора квантовых ям InGaAs.
\end{abstract}

Ключевые слова: молекулярно-пучковая эпитаксия, вертикально-излучающий лазер, гетероструктура, активная область, квантовая яма, сверхрешетка.

DOI: $10.21883 /$ OS.2019.12.48693.124-19

\section{Введение}

В течение последних лет основной прогресс в области полупроводниковых лазеров был связан с модернизацией активной области приборов. Несомненный прогресс полупроводниковых лазеров начался с использованием двойных гетероструктур, которые обеспечивали пороговую плотность тока в несколько $\mathrm{kA} / \mathrm{cm}^{2}$. За счет снижения порогового тока и, как следствие, теплового разогрева такие гетероструктуры уже могли генерировать оптическое излучение при комнатной температуре в непрерывном режиме. Дальнейший прогресс был обеспечен за счет снижения размерности активной среды. Использование лазерных гетероструктур с квантовыми ямами (КЯ), объектами с одномерным ограничением носителей заряда, позволило снизить пороговую плотность тока до $100 \mathrm{~A} / \mathrm{cm}^{2}[1]$. В дальнейшем использование лазерных гетероструктур с квантовыми точками (КТ), объектами с трехмерным ограничением носителей заряда, позволило снизить поровую плотность тока вплоть до $10 \mathrm{~A} / \mathrm{cm}^{2}$ [2]. Вместе с тем эффективное снижение величины порогового тока приводило к снижению величины максимально достижимого оптического усиления. При больших плотностях тока наблюдалось насыщение оптического усиления, и если уровень оптических потерь превышал насыщенное значение оптического усиления, то лазерная генерация не возникала. Для увеличения усиления использовались либо несколько слоев КЯ, либо несколько слоев КТ, однако в ряде случаев это не приводило к нужному результату. Так, например, если в полосковых лазерах спектрального диапазона 1310-1550 nm увеличение числа КЯ или слоев КТ практически всегда приводило к достижению лазерной генерации, то для случая вертикально-излучающих лазеров (ВИЛ) не всегда.

В лазерах полосковой конструкции световая волна взаимодействует с КЯ на всей длине резонатора, а в ВИЛ эффективное взаимодействие происходит только, когда геометрическое положение КЯ совпадает с положением пучности стоячей волны в резонаторе. По этой причине возникает характерная особенность активной области ВИЛ - ограничение ее эффективной толщины, которая обычно составляет не более половины расстояния между узлами световой волны. Для ВИЛ спектраль- 
ного диапазона $1550 \mathrm{~nm}$ эта эффективная толщина равна 80-90 nm. Таким образом, число КЯ, которые можно расположить в активной области ВИЛ, ограничено (от 6 до 8 КЯ), и, как следствие, возможность увеличения оптического усиления за счет роста числа КЯ тоже ограничена.

Для ВИЛ спектрального диапазона 1300-1550 nm характерно использование механически напряженных КЯ, которые обеспечивают увеличение коэффициента дифференциального оптического усиления, что приводит как к снижению плотности тока на пороге генерации, так и к повышению быстродействия прибора при токовой модуляции [3]. Недостатком такого подхода является необходимость использования достаточно толстых барьерных слоев, разделяющих КЯ, с целью частичной компенсации упругих напряжений, предотвращающих возникновение дислокаций несоответствия, которые ухудшают структурное качество активной области. Носители заряда в напряженных гетероструктурах локализованы только в области КЯ, а в барьерных слоях эффект усиления света отсутствует. То есть значительная часть активной области с КЯ или КТ в случае ее применения для ВИЛ не участвует в усилении света. К тому же характерные плотности пороговых токов ВИЛ спектрального диапазона $1300-1550 \mathrm{~nm}$ составляют $3-5 \mathrm{kA} / \mathrm{cm}^{2}$ [4], что соответствует области насыщения оптического усиления для гетероструктур с КЯ или КТ, и преимущество использования гетероструктур пониженной размерности для ВИЛ теряется.

В качестве альтернативы гетероструктурам со множественными слоями КТ или КЯ для активной области длинноволновых ВИЛ КЯ было предложено использовать короткопериодную сверхрешетку [5]. В настоящей работе приводятся результаты исследования структурных, оптических и усилительных свойств лазерных диодов на основе сверхрешеток спектрального диапазона $1535-1565 \mathrm{~nm}$.

Наличие в сверхрешетке минизоны, которая находится и в области ям, и области барьеров, позволяет существенно увеличить интеграл перекрытия стоячей световой волны с областью, усиливающей свет, и тем самым обеспечить существенное увеличение коэффициента оптического усиления по сравнению с гетероструктурами на основе КЯ. Повышение усиления должно положительно сказаться на быстродействии ВИЛ при прямой токовой модуляции [6]. В силу того что функция плотности состояний такой гетероструктуры имеет вид, близкий к функции плотности состояний гетероструктур на основе КЯ, существенного повышения тока прозрачности не стоит опасаться, что и нашло подтверждение в экспериментах, результаты которых излагаются далее.

\section{Эксперимент}

Для оценки усилительных свойств двух типов активных областей, используемых в длинноволновых ВИЛ, были сформированы гетероструктуры лазеров, предназначенные для торцевого вывода излучения. Гетероструктуры были изготовлены методом молекулярнопучковой эпитаксии (МПЭ) на установке Riber MBE49 компанией ООО „Коннектор Оптикс“ на подложках InP (100). Структурное качество гетероструктур исследовалось методом рентгенодифракционного анализа. Измерения спектров рентгеновской дифракции с высоким разрешением были проведены вблизи симметричного рефлекса (004) InP на дифрактометре PANalytical X'PertPro в параллельной геометрии пучка рентгеновского излучения. В качестве источника излучения (мощностью $6 \mathrm{~kW}$ ) использована трубка с вращающимся медным анодом $(\lambda=0.15406 \mathrm{~nm})$. Полуширина первичного пучка не превышала $12^{\prime \prime}$, что обеспечивалось использованием четырехкратного $\mathrm{Ge}$ (220) прорезного кристалла-монохроматора.

Эпитаксиальная лазерная гетероструктура состояла из эмиттера $\operatorname{In}_{0.52} \mathrm{Al}_{0.48} \mathrm{As} n$-типа толщиной $1000 \mathrm{~nm}$, волновода $\mathrm{In}_{0.53} \mathrm{Ga}_{0.27} \mathrm{Al}_{0.2} \mathrm{As}$ толщиной $600 \mathrm{~nm}$, в центр которого была помещена активная область, эмиттеpa $\mathrm{In}_{0.52} \mathrm{Al}_{0.48} \mathrm{As} p$-типа толщиной $1500 \mathrm{~nm}$ и контактного слоя $\operatorname{In}_{0.53} \mathrm{Ga}_{0.47} \mathrm{As}$ p-типа толщиной $200 \mathrm{~nm}$. Конструкция гетероструктуры активной области № 1 содержала 7 механически напряженных $\operatorname{In}_{0.74} \mathrm{Ga}_{0.26} \mathrm{As}$ КЯ толщиной $2.8 \mathrm{~nm}$, разделенных нелегированными $\mathrm{In}_{0.53} \mathrm{Ga}_{0.27} \mathrm{Al}_{0.2} \mathrm{As}$-барьерами толщиной $12 \mathrm{~nm}$ [7]. Конструкция гетероструктуры активной области № 2 представляла собой сверхрешетку на основе квантовых ям $\operatorname{In}_{0.57} \mathrm{Ga}_{0.43} \mathrm{As}$ с потенциальными барьерами $\mathrm{In}_{0.52} \mathrm{Ga}_{0.27} \mathrm{Al}_{0.21} \mathrm{As}$. Число повторений слоев в сверхрешетке составляло 29, толщина КЯ $2.5 \mathrm{~nm}$, толщина потенциальных барьеров $1.2 \mathrm{~nm}$. Таким образом, исследуемые активные области имели близкие толщины и составы. Экспериментальные и модельные рентгенодифракционные кривые сформированной гетерострукту-

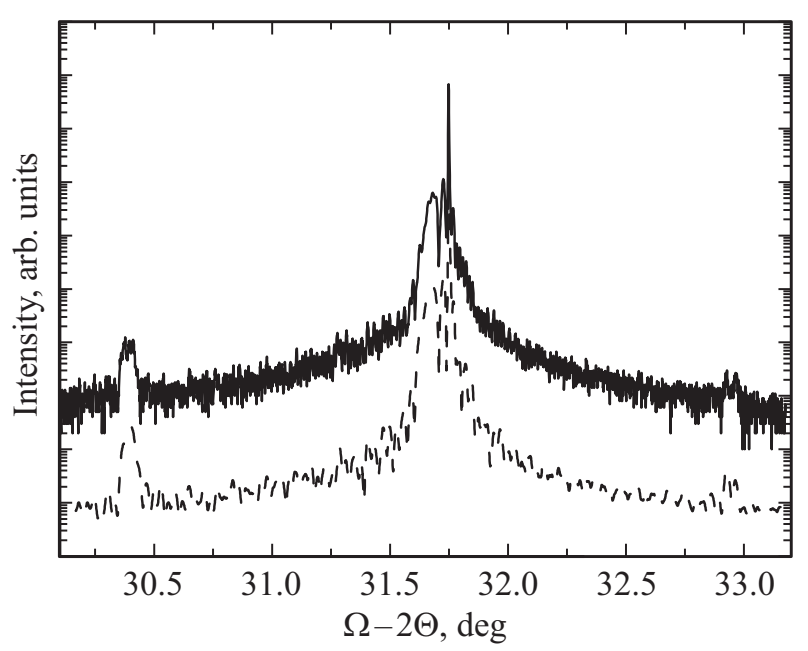

Рис. 1. Рентгенодифракционные кривые гетероструктуры лазера с активной областью на основе сверхрешетки (гетероструктура № 2). Экспериментальная кривая (сплошная линия, вверху); расчетная кривая (штриховая линия, внизу). 
ры № 2 представлены на рис. 1. Наиболее интенсивный пик из наблюдаемых на кривой качания соответствует подложке InP. Слева от него в области меньших углов наблюдается пик дифракции эмиттерных слоев InAlAs и еще левее центральный пик дифракции сверхрешетки $\mathrm{InGaAs} / \mathrm{InGaAlAs,} \mathrm{а} \mathrm{по} \mathrm{бокам} \mathrm{видны} \mathrm{сателлитные} \mathrm{пики}$ сверхрешетки. В результате моделирования экспериментальной кривой качания были определены параметры эпитаксиальных слоев гетероструктуры, которые совпали с заданными значениями. Средняя мольная доля индия в сверхрешетке составила 0.56 .

Из гетероструктур были изготовлены лазеры Фабри-Перо полосковой конструкции с шириной полоскового контакта $100 \mu \mathrm{m}$ и различными длинами лазерного резонатора и проведен анализ их характеристик. Монтаж лазеров на медный теплоотвод осуществлялся эпитаксиальными слоями вниз. Спектры излучения измерялись при накачке импульсами тока (длительность импульса $1 \mu \mathrm{s}$, частота повторения $1 \mathrm{kHz})$, вольт- и ватт-амперные характеристики измерялись при непрерывной накачке, температура теплоотвода стабилизировалась на уровне $25^{\circ} \mathrm{C}$.

\section{Результаты и обсуждение}

На рис. 2 представлены типичные спектры многомодового излучения лазеров с длиной резонатора $L=1000 \mu \mathrm{m}$, изготовленных из гетероструктур № 1 и № 2 , при токе накачки $I=2$ А. Измерения ватт-амперных характеристик лазеров с длиной резонатора $250-1000 \mu$ m показали, что пороговый ток варьирует в диапазоне $1-3 \mathrm{kA} / \mathrm{cm}^{2}$ в зависимости от типа гетероструктуры и длины резонатора.

Расчет модального усиления $G_{\bmod }$ проводился аналогично [7]. На пороге лазерной генерации усиление равно сумме всех потерь $[8]$

$$
G_{\text {mod }}=\alpha_{\text {in }}+\alpha_{\text {out }},
$$

где $\alpha_{\text {in }}-$ потери излучения внутри резонатора, $\alpha_{\text {out }}-$ потери на выход излучения из резонатора, которые описываются формулой [8]:

$$
\alpha_{\text {out }}=\frac{1}{2 L} \ln \frac{1}{R_{1} R_{2}},
$$

где $L-$ длина резонатора, $R_{1}$ и $R_{2}-$ коэффициенты отражения зеркал резонатора.

Дифференциальная квантовая эффективность $\eta_{d}$ пропорциональна отношению потерь на выход излучения из резонатора к сумме всех потерь в резонаторе [8]:

$$
\eta_{d}=\frac{\eta_{\text {int }} \alpha_{\text {out }}}{\alpha_{\text {in }}+\alpha_{\text {out }}}
$$

где $\eta_{\text {int }}-$ внутренняя квантовая эффективность вынужденного излучения. Из (1) и (3) следует, что можно определить величину модального усиления:

$$
G_{\mathrm{mod}}=\frac{\eta_{\mathrm{int}} \alpha_{\mathrm{out}}}{\eta_{d}}
$$

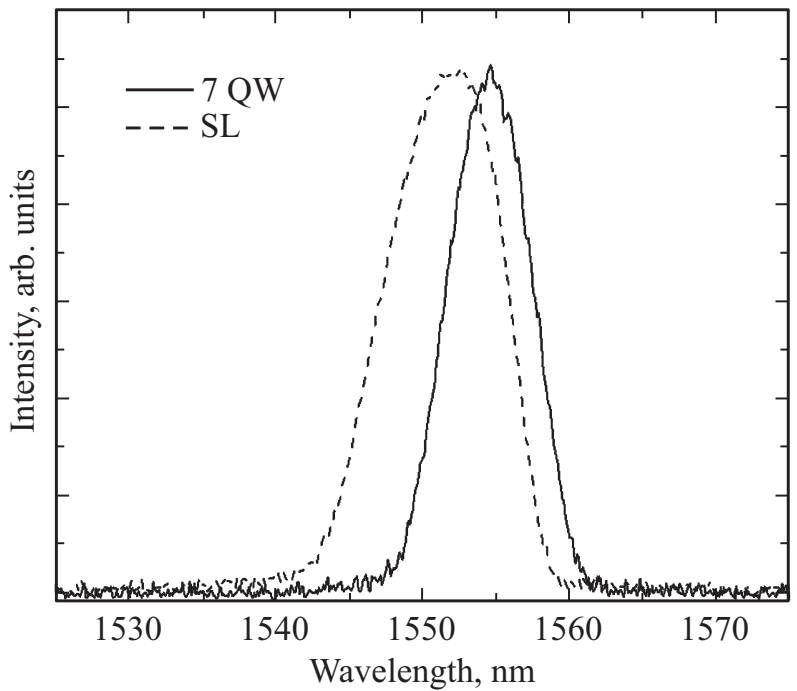

Рис. 2. Типичные спектры излучения лазеров полосковой конструкции с длиной резонатора $L=1 \mathrm{~mm}$, изготовленных из гетероструктур с активной областью на основе 7 КЯ (сплошная линия) и активной областью на основе сверхрешетки (штриховая линия). Ток накачки $I=2 \mathrm{~A}$, температура $25^{\circ} \mathrm{C}$.

Таким образом, измерив дифференциальную квантовую эффективность и длину резонатора лазера, можно численно определить величину $G_{\bmod } / \eta_{\text {int. }}$. Конструкция исследуемых гетероструктур одинакова и отличается только активной областью, поэтому можно предположить, что величина $\eta_{\text {int }} \approx 1$ (или по крайней мере несильно отличается в исследованных гетероструктурах), тогда величина $G_{\text {mod }} / \eta_{\text {int }} \approx G_{\text {mod }}$.

Зависимости величины модового усиления $G_{\bmod }$ на пороге лазерной генерации от плотности тока накачки, определенные в ходе эксперимента и рассчитанные с учетом формул (1) и (3), представлены на рис. 3 (круги соответствуют активной области на основе 7 КЯ (гетероструктура № 1), квадраты - лазеру с активной областью на основе сверхрешетки (гетероструктура № 2), линии соответствуют аппроксимации экспериментальных точек, выполненной по формуле (5) [9]

$$
G_{\text {mod }}=G_{0 J} \ln \left(J_{\text {th }} / J_{\text {tr }}\right),
$$

где $J_{\text {th }}-$ пороговая плотность тока, $J_{\text {tr }}-$ плотность тока прозрачности, $G_{0 J}-$ коэффициент материального оптического усиления. Такая аппроксимация позволила оценить величины плотности тока прозрачности для каждой гетероструктуры, которые составили 830 и $720 \mathrm{~A} / \mathrm{cm}^{2}$ для гетероструктур № 1 и № 2 соответственно. Видно, что значение тока прозрачности в исследуемой гетероструктуре со сверхрешеткой не превышает значения для гетероструктуры с 7 КЯ.

Из рис. 3 видно, что активная область на основе сверхрешетки демонстрирует бо́льшее усиление при равных значениях плотности тока накачки по сравнению с активной областью на основе набора из 7 КЯ. Так, 


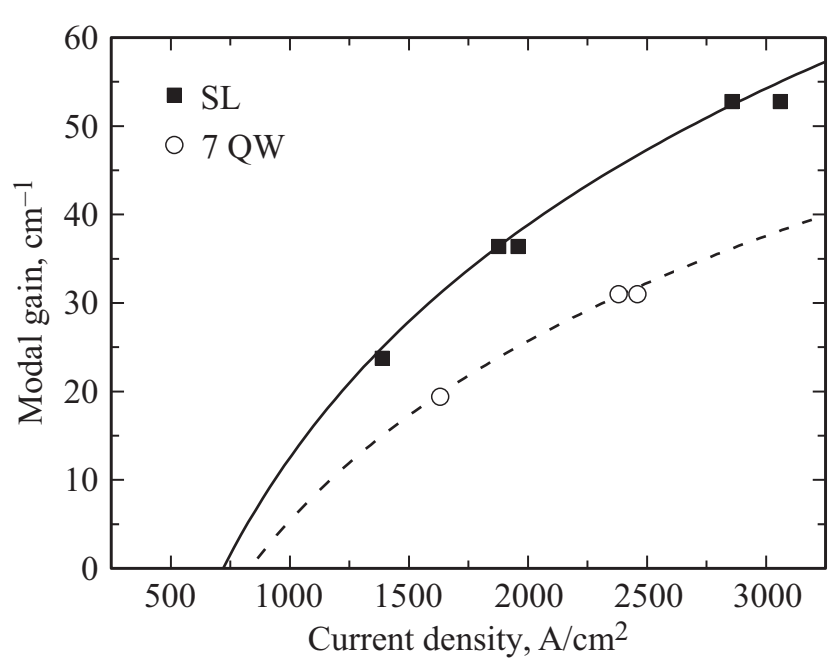

Рис. 3. Зависимости величины модального усиления $G_{\bmod }$ на пороге лазерной генерации от плотности тока накачки. Круги соответствуют активной области на основе 7 КЯ (гетероструктура № 1), квадраты - лазеру с активной областью на основе сверхрешетки (гетероструктура № 2), линии соответствуют аппроксимации экспериментальных точек). $W=100 \mu \mathrm{m}$, $\lambda=1550 \mathrm{~nm}$.

при плотности тока накачки $3000 \mathrm{~A} / \mathrm{cm}^{2}$, характерной для порога генерации ВИЛ, усиление в гетероструктуре на основе сверхрешетки составляет $49 \mathrm{~cm}^{-1}$, а в гетероструктуре с 7 КЯ всего $33 \mathrm{~cm}^{-1}$, что примерно в 1.5 раза ниже. Таким образом, полученные результаты позволяют утверждать, что замена активной области на основе 7 КЯ ВИЛ на активную область на основе короткопериодной сверхрешетки InGaAs/InGaAlAs должна позволить улучшить характеристики ВИЛ, снизить значения пороговых токов и повысить быстродействие [4].

\section{Заключение}

В результате проведенных исследований лазеров полосковой конструкции показано, что активная область на основе короткопериодной сверхрешетки $\mathrm{In}_{60} \mathrm{Ga}_{0.40} \mathrm{As} / \mathrm{In}_{0.53} \mathrm{Ga}_{0.27} \mathrm{Al}_{0.20} \mathrm{As}$ обладает бо́льшим усилением при равных значениях плотности тока в сравнении с активной областью на основе 7 механически напряженных КЯ $\mathrm{In}_{0.74} \mathrm{Ga}_{0.26} \mathrm{As}$. Таким образом, использование в длинноволновых ВИЛ спектрального диапазона $1535-1565 \mathrm{~nm}$ активной области на основе короткопериодной сверхрешетки может привести к повышению динамических характеристик ВИЛ, уменьшению величины порогового тока по сравнению с длинноволновыми ВИЛ, где в качестве активной области используется набор КЯ [4].

\section{Финансирование работы}

Работа выполнена при поддержке Министерства науки и высшего образования России, федеральная целевая программа „Исследования и разработки по приоритетным направлениям развития научно-технологического комплекса России на 2014-2020 годы“, соглашение о предоставлении субсидии от 26.09.2017 г. № 14.578.21.0253, уникальный идентификатор RFMEFI57817X0253.

\section{Конфликт интересов}

Авторы заявляют, что у них нет конфликта интересов.

\section{Список литературы}

[1] Alferov Z.I. // Semiconductors. 1998. V. 32. P. 1-14. doi $10.1134 / 1.1187350$

[2] Park G. et al. // IEEE Photonics Technol. Lett. 2000. V. 12. N 3. P. $230-232$. doi $10.1109 / 68.826897$

[3] Ortsiefer $M$. et al. // Vertical-Cavity Surface-Emitting Lasers XVI, SPIE OPTO. San Francisco, 2012. P. 82760A.

[4] Babichev A.V. et al. // IEEE J. Quant. Electron. 2017. V. 53. N 6. P. 1-8. doi 10.1109/JQE.2017.2752700

[5] Бабичев А.В. и др. Гетероструктура вертикально-излучающего лазера: пат. 188629 RU. Россия, 2019.

[6] Spiga S. et al. // 5th IEEE Photonics Soc. Opt. Interconnects Conf. OI 2016. 2016. P. 14-15.

[7] Kolodeznyi E.S. et al. // Opt. Spectrosc. 2018. V. 125. N 2. P. 238-242. doi 10.1134/S0030400X18080143

[8] Casey H.C., Panish M.B. Heterostructure Lasers: Part B. Academic P. N. Y:: Academic press, 1978. 336 p.

[9] Coldren L.A., Corzine S.W., Mashanovitch M.L. Diode Lasers and Photonic Integrated Circuits. N. Y.: John Wiley \& Sons, 2012. 744 p. 